\title{
Market Information to Promote Agricultural Investment: The Challenge
}

\section{A Jooste and J A Groenewald}

Department of Agricultural Economics, University of the Orange Free State

\section{ABSTRACT}

The move towards more competitive agriculture in South Africa, largely unburdened by regulatory constraints, is characterised by an undersupply of relevant information in some cases and inadequate access to it in others. This affects the heartbeat of production, investment, financial and strategic decisions. The very nature of intersectoral agricultural linkages, as well as the differences between specific interest groups, suggest that information needs are likely to differ too. There is, however, a common objective - direct or indirect - for all the users of agricultural information. This is to maximise the returns to investment in the short, medium and long run. However, there exist various problems in providing information, which impedes the ability of information users to position themselves strategically in order to maximise returns.

JEL Q 13

It is a capital mistake to theorise before one has data Arthur Conan Doyle, 1930.

\section{INTRODUCTION}

The gradual deregulation of agriculture during the 1970s and 1980s gained momentum during the 1990s and culminated in the repeal of the Marketing Act of 1937 as amended, and the promulgation of the Marketing of Agricultural Products Act of 1996. Furthermore, South Africa complied with the Marrakesh Agreement reached under the auspices of the General Agreement on Tariffs and Trade (GATT), now known as the World Trade Organisation (WTO). These rapid changes (see e.g., Brand et al. 1992; Vink, 1993; Jooste \& Van Zyl, 1998) caused unprecedented changes in agricultural structure and management in South Africa. At the same time, competition from overseas commodities increased substantially, whilst domestic producers and agribusiness are seeking new market opportunities abroad. 
Ironically, the move towards more competitive agriculture in South Africa unburdened by regulatory constraints, is characterised by an undersupply of relevant information in some cases, and inadequate access in others - affecting the very heartbeat of production, investment, financial and strategic decisions. For example, before the abolishment of the agricultural control boards that had regulated agricultural markets for decades, agricultural outlook conferences (AGROCON) were held annually since 1977, but discontinued after the abolishment of the control boards - at a time when they are really needed. AlSudeary (1982) cited by Van Niekerk (1995), goes further by stating that agriculture has the somewhat dubious distinction of being that field of human endeavour which exhibits the greatest gap between available knowledge and that what is actually practised. Frick and Groenewald (1998) conclude that in South Africa, the official suppliers of agricultural data are not providing the necessary data that decision-makers, both public and private, in fact need. This state of affairs is disturbing when one considers that good information improves the competitiveness and the efficiency of markets (Salin, Thurow \& Elmer, 1996), and that the lack of information was, in the $1930 \mathrm{~s}$, cited as an important reason for the passage of the Marketing Act.

\section{THE NEED FOR AGRICULTURAL INFORMATION}

The very nature of intersectoral agricultural linkages, as well as the differences that exist amongst specific interest groups suggest that information needs are likely to differ. Wu, Just, Zilberman and Wolf (1999) state that since different groups make different kinds of decisions, one would also expect to see different information-seeking behaviour on the part of each group. There is, however, a common aim - direct or indirect - among all the users of agricultural information namely, to maximise the returns to investment in the short, medium and long run (see e.g. Frick \& Groenewald, 1998; Russell, 1983; Craig, 1979). For example, policy makers need information to create the necessary environment for sustainable agricultural production, marketing and trade in order to promote investment. Producers, on the other hand, have to make decisions on what to produce, what inputs to use, the combination of inputs and marketing channels necessary to maximise the return on capital. For this they need information. Moreover, Craig (1979) mentions that "it is also important to recognise that one person may fulfil many roles ... and may apply different criteria when acting in his different roles". This should be taken into account by information providers.

Furthermore, asymmetric information usually gives rise to different bargaining positions in the market. This may cause market failure, which in turn might result in more policies to regulate trade. However, if information is available on a symmetric basis, this could serve as a countervailing power to market failure. 
Hence, instead of policies designed to counter market failure, government should create an environment where information can be accessed by all participants in the market.

\section{3}

\section{THE CRITICAL "VACUUM"}

Having access to information sources is one thing, knowing how to best use them is another thing altogether (Metcalfe, 1988). This is emphasised by Shultz (1975) who states that differences in capacity to process information are a major source of variation in human capital. He also argues that differences in human capital could easily lead to the exclusion of certain users in information markets. This phenomenon is illustrated by Van Niekerk (1995) who states that although the information necessary to increase production levels is generally available, very few countries in Africa are self sufficient in food production; the challenge for African information workers is to close the communication gap between theory and practise. In fact, Klair, Boggia and Richardson (1998) state that providing information has become the most important part of extension activity. Amongst other things, information entails training sessions, demonstrations in the field, and assessment, together with farmers, of the activities and results obtained. Aina (1995) regards repackaging and dissemination of information as crucial to the provision of relevant and timely information to agricultural information users. In his view, this is the crux of the matter as it is the main source of the problem of providing agricultural information in Africa. ISNAR (1993) reinforced this view by mentioning that the linkage between information staff and their clients is the weakest part of the information management chain. This state of affairs will undoubtedly have a negative influence on investment decisions and consequently the returns to canital. This could eventually result in disinvestment in a sector of great importance for sustainable economic development, especially in Sub-Saharan African countries.

\section{DIVERSITY OF INFORMATION NEEDS}

The agricultural sector consists of many industries, with firms functioning at all levels of the farm-to-consumer market channel. Some specialise in particular commodities while others produce, distribute, or sell a mix of products. Some also specialise in one marketing function, for example wholesaling or procurement; other are vertically integrated. All these firms require information to assess their performance and formulate long-range plans in dynamic, competitive markets (Krueger and Salin, 1998). Successful firms realise the necessity of information in striving for differential advantage, which is the basis of modern competition. It is, however, important to take cognisance of the fact 
that marketing channels for firms/producer operations encompass various organisational forms and sizes with different levels of human capital and infrastructure. This will influence their demand structure for primary data and value added information.

According to Aina (1995) the majority of farmers in Africa live in rural areas where the infrastructure necessary for access to information is lacking or minimal. In addition, the majority of the farmers cannot read or write any language. Still they form part of a complex marketing system and have to position themselves accordingly. This emphasises the importance of literacy and numeracy training which should be part and parcel of a development strategy in rural areas. Wu et al. (1999) mention that one way to differentiate between information on the same subject is by how easy it is to understand. For example, a large firm may have the human capital to diagnose huge matrices of numbers to make production decisions, while small farmers may need something more prescriptive to make the same decision. A small farmer may hire a consultant or subscribe to an agricultural newsletter that contains advice for the farmer.

This state of affairs is also applicable to South A frican agriculture, particularly when one considers its dualistic nature. Van Niekerk (1995) mentions that history has left South Africa with a legacy of two societies, namely a "first world" or "developed" sector, and a "third world" or "developing" sector. The former has the characteristics of a post-industrial or information society, whereas the latter is mostly a rural subsistence economy aimed at selfsufficiency (Zaaiman, 1985 as cited by Van Niekerk, 1995). The result is that there are large differences in objectives between the various agricultural sectors in South Africa, and hence their business decisions. However, there are similarities in their informational needs. Both commercial and subsistence farmers need information on input prices, markets for their surplus produce, the weather, and so on. The major differences are the way in which information is disseminated and the format (nature) of the information. An information system should cater for such differences.

Notwithstanding the above, it should be noted that different sub-sectors will have different information needs. Frick and Groenewald (1999) investigated the agricultural statistics needs of agribusinesses in South Africa. They concluded that, although there are similarities in the information needs of different subsectors in agriculture, there are also considerable differences. For example, the need for statistics on the volume of production, area planted, cost of production, and so on, are rather similar for the field crop and horticultural sectors, but statistics on the quantity of imports and exports are considered more important for field crops. Producer prices, on the other hand, are more important for the 
horticultural sector. Frick and Groenewald (1999) also found differences with regard to the time when information is needed. According to Wu et al. (1999) these differences can be traced to the fact that markets for different commodities behave in different ways. Furthermore, different jobs within different commodity chains can require completely different qualities and attributes of information. Even for the same job, there may be differences in ability and understanding which cause a party to choose a specific type of information (Wu et al., 1999). It is of decisive importance for information providers to recognise these differences, since each person in a firm contributes directly or indirectly to the positive/negative returns on capital. The old proverb comes to mind: "A chain is only as strong as its weakest link".

\section{INFORMATION AND VERTICAL INTEGRATION: IMPLICA- TIONS FOR INVESTMENT}

Coase's insight into the nature of the firm as cited by Leathers (1999), provides another dimension of the ongoing debate on the information issue. He states that vertical integration of processes takes advantage of the fact that information within the firm is cheaper to collect and verify than in the market. This is, however, not an absolute principle, otherwise firms would integrate fully from one end of the production and marketing chain to the other. At some point, technological or managerial diseconomies outweigh the informational advantages of further vertical integration (Leathers, 1999).

In an essay on "Information asymmetry as a reason for vertical integration", Hennesy (1997) gives an overview of the reasons for vertical integration, and specifically considers market failure in conveying information about quality as a reason for vertical co-ordination. According to him, the incentive to invest in ensuring quality is reduced relative to the perfect information scenario, because the difference in market revenues is lower than that which would maximise social surplus. As a result, underinvestment in the provision of quality occurs, and this may occur particularly for crops where it is difficult and/or costly to detect quality differences. The reason is that imperfect information constitutes an externality. By increasing the average quality of a product, investing firms provide benefits that the market does not fully reward. Vertical integration and, to a lesser extent, production contracts solve this problem because they remove the need to test for quality (Hennesy, 1997).

This situation is shown in Figure 1. Note that information has benefits in terms of productivity and/or money, as well as costs. If the firm's information is less than $O A$ in Figure 1, say $O B$, then the firm will try to increase it to $O A$. In other words, the firm should always strive to the point where the Marginal Value 
Product (MVP) of information is equal to its Marginal Factor Cost (MFC). One may find that a situation can arise where business decisions have to be made without sufficient information. This will lead to forced action, and a higher probability of non-optimal decisions.

\section{Figure 1 The optimal level of information}

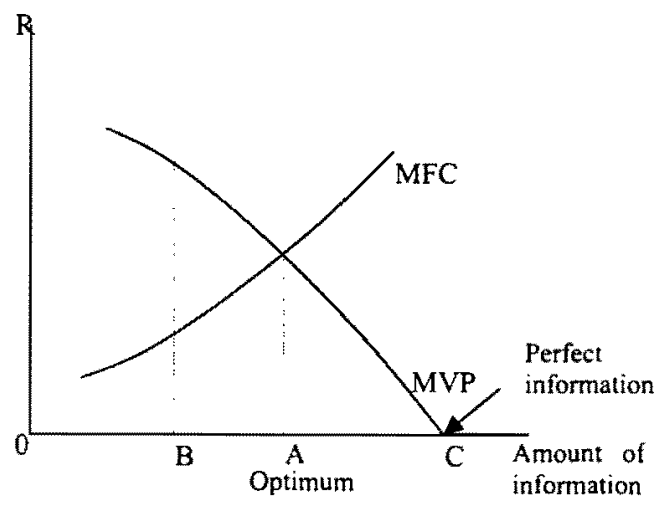

The main issue of concern is that by internalising the information problem, firms can overcome certain information failures. The extent to which firms can integrate is, however, also dependent on their ability to obtain and use information. In other words, the abilities (e.g. inborn ability, literacy, education, etc.) of firms (managers) to use and obtain information will differ. This will again influence the optimal level of information between firms. Figure 2 demonstrates this situation. Th: differences between the level of optimal information used by the two firms stems from differences in their marginal factor cost and marginal value product of information. This is again a function of the type of firm and the level of management. 


\section{Figure 2 Differences in the level of optimal information between firms}

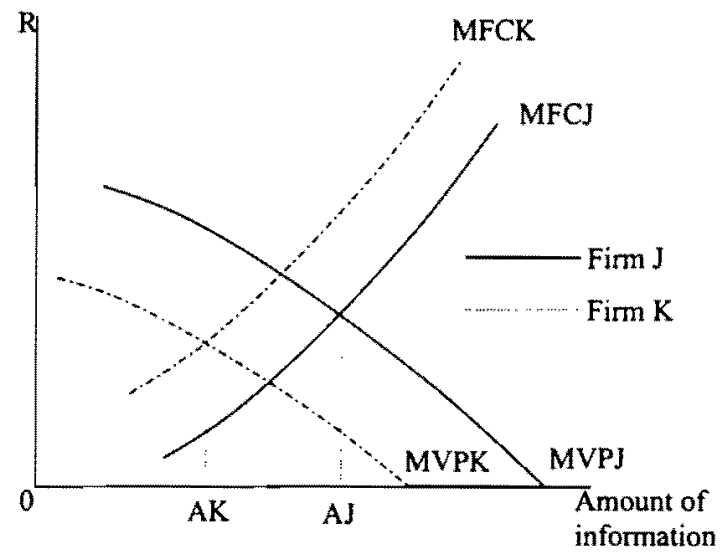

\section{INFORMATION AND THE SOUTH AFRICAN FARMER}

\subsection{Government vs. private information suppliers}

There is a growing demand for value-added information by farmers in South Africa. This is not surprising, seeing that the market in which they operate is quite different from what they were used to before 1996. This holds for both commercial and small-scale farmers, although the method of information dissemination may differ. Value-added information is used by varions parties in the agricultural sector to make informea decisions. Information can take various forms, and varies from market analysis and forecasts for different commodities, to the social and economic impact of trade agreements and the effect of climate on the production of certain commodities in various geographical regions. Value-added information is furthermore usually tailor-made to specific needs and comes at a price for this reason. This means that certain may be excluded from sharing vital information. A possible remedy for this problem may be to internalise the value-adding function, but this again introduces a new set of problems, since the production of value-added information requires relatively highly skilled personnel, the necessary infrastructure and access to data networks. This can be rather costly. Here the government can play a most important role, by extending the capacity to provide certain value-added services. This is not to say that government should take over the role of private entrepreneurs, but it might provide the means of better communication between information providers and users. Certain government functions can even be 
outsourced to the private sector, with conditions attached that would further the aims of government in the information system. Outsourcing may cause the system to be more effective and efficient, provided that competition exists between information providers.

Wu et al. (1999) state that it has been argued that government provision of information drives private information providers out of business, and undermines the market mechanism. It does, however, rather seem that government provides the very general information input used by private information providers to bring a specialised piece of information to a specific audience. The heterogeneity of the demand for information allows information suppliers to make a profit, despite government provision of information on the same topic for free. In a study conducted by Wu et al. (1999) in the US, it was shown that intermediaries, such as extension workers, rely heavily on the government for information, but that end users do not - this is strong evidence that government information does not drive private information sources out of business, but rather makes their role economically viable.

It should be noted that if the government plays a too small part, this will certainly be to the disadvantage of the very farmers and businessmen which government in South Africa wish to promote: The poor, small and emergent. Private companies are likely to concentrate where profit opportunities are best. The small, poor and emerging farmers and businessmen will be neglected. This process has been described as "creaming" (Kolderie, 1986).

Metcalfe (1989) also mentions that the trouble with information is that many think they know all about it and can do something to improve on it - the result, inevitably, is chaos. He points out that there is much praisewnrthy but uncoordinated effort. The challenge to information providers therefore lies in establishing a co-ordinated effort to supply relevant and timely information to a heterogeneous population of information users. This should not only enhance the efficiency with which information providers use their limited resources to provide information to specific target groups, but the target groups themselves would be in a better position to make strategic investment and marketing decisions.

\subsection{The growing importance of informal information}

Farmers constantly need information on a great variety of issues, for example, market prices of inputs, price movements, production prospects, cost and sources of capital, domestic and international market opportunities and dangers, as well as the availability and cost of natural resources. These data needs can be satisfied by sourcing information from either public or private information 
providers. Furthermore, one should consider the formal or informal nature of information. Wu et al. (1999) define informal information as information that one cannot buy with money, but for which one must find time through conversation. Personal observations will be part of this. With the deregulation of the Meat Board certain information ceased to exist, for example, accurate herd and slaughter numbers. Estimates of this must typically be found in an informal manner. Thus in the absence of a market for certain kinds of information, a firm could be driven to obtain the information through conversation with customers, or even competitors. To take another example, a firm may observe fruit orchards to derive an estimate of prospective yield. It could also be that a firm, after obtaining formal information, will use informal means to check the accuracy of the information. In this way, informal information could increase the marginal value product (MVP) of the formal information (Wu et al., 1999). This would then influence the decisions made by farmers.

Amstutz (1998) mentions that as government intervention in agriculture continues to decrease worldwide, the need for reliable statistical information by all those involved in the business of agriculture will grow. This entails the investment of human capital and other resources by private firms, to obtain the information specific to their own needs. Important in this regard is that information that is specific enough to be valuable is often proprietary information (Salin et al., 1986). The result is that certain information will only be available to a certain (monopolistic) group, although there may be a wider demand for such information. Conversely, several (smaller) groups may invest in information-gathering to obtain the same information. This, however, again raises the issue how co-ordination can be achieved without wasting time and money. As already mentioned, firms will tend to use information tailored for their specific markets and conditions and will protect such information, but the question is whether the basic information should also be exclusive to a specific group. If the information system is private, exclusivity should go to those who pay for it. This problem may be overcome by public funding of basic information, but again resistance can be expected in cases with a high degree of industrial concentration. The basic problem is that one group can exclude other users from basic information through its market power, thus raising the cost (time and money) of gathering informal information. This cost may be prohibitive. Hence, smaller firms may eventually turn too less accurate sources of information for their business and investment decisions. The consequences of this may be even more costly. 


\subsection{Future markets as means of transmitting private information}

Just (1983) quotes various authors who have demonstrated that, if futures markets are efficient and have no basis risk, then futures prices are the best price expectation that can be used to determine commercial decisions. Even when basis risk is admitted, future market expectations are the only expectations that consistently lead to non-involvement of individual commercial decision makers in futures trading in the absence of transaction costs (Just, 1983). Since the transaction costs of futures trading are generally low, these arguments presumably also more or less hold when transaction costs are considered. Just (1983) concludes that the fact that many commercial decision makers consistently do not trade in futures contracts, suggests that futures markets are indeed serving as instruments, directly and indirectly, for transmitting information to commercial decision makers. The question then arises whether futures markets are efficient, but the answer falls outside the scope of this paper. What can be said, however, is that futures prices of the South African Futures Exchange (SAFEX) in South Africa, maize in particular, are regarded as an important proxy for maize prices, and are widely quoted by various information providers. The extent to which this provides guidance to small-scale farmers in their decision-making processes remains an open question. One can presumably expect that these farmers rarely use futures prices, mainly due to the lack of organisational capacity to react to information transmitted to them via this medium - that is, if the information actually reaches them in time to make informed decisions. A general lack of understanding of future markets by all farmers is one reason why they do not adequately hedge against "investment" risks. This presents a major challenge to all information providers.

\section{CHALLENGES FOR THE FUTURE}

According to Bonnen (1975), an information system should include not only a data system, but the analytical and other capabilities necessary to interpret data. This is not to say that all capacity should be located at one central point, but rather that a co-ordinated effort in the management of information at different levels should receive the greatest attention in order to meet the information needs of a heterogeneous population. It is most important to bridge the information gap, as was repeatedly stressed in this paper. This gap exists not only between information providers and users, but also amongst providers and users. This source of inefficiency seriously impedes the effort to increase returns on investment, whether it is investment in human capital, business and even information itself. 
Metcalfe (1989) mentions that planning for information requires knowledge of the following:

- Existing/potential users - who they are and what are their needs?

- What information sources exist, which can one reach, and how can new sources be created and maintained?

- How to extract and analyse information from a combination of sources; and

- How to communicate the required information to the users.

These issues relate directly to what Lindner (1998) sees as reasons for the shortcomings of information systems. They are:

- Information systems work in relative isolation from each other;

- Institutional rigidity, not sufficiently adaptive to changed statistical needs of the present and likely changes in the future;

- Lack of effective communication between providers and users;

- Growing resource constraints; and

- Sub-optimal use of (available) information technology.

Lindner also suggests three avenues that seem worthwhile to explore - jointly if possible - in order to improve the state of information services:

- Establish a forward-looking needs profile of statistics that are seen as the key to answering today's policy questions and those which are likely to become more important over the medium term;

- Review the ability of the system to meet needs and identify necessary steps to ensure better planning, co-ordination and synergy; and

- Optimise the use and proper application of information technology for database management.

There rests an obvious and enormous responsibility on information providers in South Africa to reconcile the need for and supply of information.

\section{CONCLUSION}

The South African agricultural sector at present experiences a great need of a well structured information system that encompasses the dualistic and heterogeneous information user population. This paper has discussed some important issues that need to be considered by all information providers. These include a proper inventory of specific needs, much improved co-ordination of effort and, probably the most important, closing the information gap between the various parties involved. The issues that need to be addressed are complex in 
nature and would require a joint effort by both information suppliers and users to establish a system capable of catering for different user needs in order to facilitate different investment decisions on a sustainable basis.

\section{REFERENCES}

1 ANA, L.O. (1995) "Information and Agriculture in Africa", Chapter 1: 1-11 in Agricultural Information in Africa, Aina, L.O., Kaniki, A.M. and Ojiambo, J.B. (eds.) Third World Information Service Limited.

2 AMSTUTZ, D.G. (1998) "Agricultural Statistics for Private and Global Marketing", Paper presented at the Agricultural 2000 Conference, Washington D.C., March 18-20, 1998.

3 BONNEN, J.T. (1975) "Improving Information on Agriculture and the Rural Life", American Journal of Agricultural Economics, 57: 753-63.

4 CRAIG, G.M. (1979) "Information Systems in UK Agriculture", Final Report of the Agriculture Information Review Committee. British Library Research and Development Reports, Report No 5469 (1979).

FRICK, A. and GROENEWALD, J.A. (1998) "The Need for Agricultural Information in the New South Africa", Agrekon 38(2): $241-54$.

FRICK, A. and GROENEWALD, J.A. (1999) "Agricultural Statistics Needs of Agribusinesses in South Africa", Paper presented at the $37^{\text {th }}$ AEASA Conference, September 28-30, 1999.

7 HENNESSY, D.A. (1997) "Information Asymmetry as a Reason for Vertical Integration", in Strategy and Policy in the Food System: Emerging Issues, Caswell, J.A. and Cotterill, R.W. (eds.) Proceedings of NE-165 Conference, June 20-21, 1996.

8 JUST, R.E. (1983) "The Impact of Less Data on the Agricultural Economy and Society", American Journal of Agricultural Economics, 65: 872-81.

9 KLAIR, K.; BOGGIA, A. and RICHARDSON D.W. (1998) "The Changing Information Needs of Farmers in the US and Europe", $6^{\text {th }}$ Joint Conference on Food, Agriculture and the Environment, Minneapolis, Minnesota, August 31 to September 2, 1998.

10 KRUEGER, A. and SALIN, V.D. (1998) "Management and Information at U.S. Agribusiness: Perspectives from a Cattle-Beef Sector", Faculty Paper Series 98-3, Texas A\&M University, Texas.

11 KOLDERIE, T. (1986) "Two Different Concepts of Privatisation", Public Administration Review, July - August 1986: 285-90.

12 LEATHERS, H.D. (1999) "What is Farming? Information, Contracts and the Organisation of Agricultural Production: Discussion", American Journal of Agricultural Economics, 81(3): 621-3. 
13 LINDNER, A. (1998) "Issues and Concerns for Developed Countries", Paper presented at the Agricultural 2000 Conference, Washington D.C., March 18-20, 1998.

14 METCALFE, J.R. (1989) "Strategic Issues in Agricultural Information, with Special Reference to Developing Countries" IAALD Quarterly Bulletin, Vol 34(3): 113-17.

15 RUSSELL, H.M. (1983) "Agricultural User Populations and their Information Needs in the Industrialised World", Quarterly Bulletin of IAALD Vol 28(2): 40-52.

16 SALIN, V.; THUROW, A.P. and ELMER, N. (1996) "A Preliminary Survey of Users of Agricultural Economics Information: Procedures and Results", Faculty Paper Series 97-4 Texas A\&M Univerity, Texas.

17 SHULTZ, T. (1975) "Value of the Ability to Deal with Equilibria", Journal of Economic Literature, 13(3): 7-846.

18 VAN NIEKERK, R.V. (1995) "The State of Agricultural Information Services in South Africa", Chapter 5: 57-66, In Agricultural Information in Africa, Aina, L.O., Kaniki, A.M. and Ojiambo, J.B. (eds.) Third World Information Service Limited.

19 VINK, N. (1993) "Entrepreneurs and the Political Economy of Reform in South African Agriculture", Agrekon, 32(4): 153-66.

20 WU, S.; JUST, D.; ZILBERMAN D. and WOLF, S.A. (1999) "Demand for Agricultural Information", American Agricultural Economics Association Annual Meeting, August 1999. 